\title{
Models of species abundance: a critique of and an alternative to the dynamics model
}

\author{
Manuel Barangé, Begoña Campos \\ Instituto de Ciencias del Mar, Paseo Nacional s/n, E-08039 Barcelona, Spain
}

\begin{abstract}
Species abundance patterns in natural communities were analyzed using the recently described 'dynamics model' Although the dynamics model is based on biological processes, simulation of which yields patterns similar to those reported for natural communities, 3 shortcomings to the model have been identified: (1) patterns identical to those predicted can also be derived for non-biological communities; (2) the examples presented to validate the model are inadequate to assert with certainty that competition is actually the factor responsible for the said patterns, as the model predicts; and (3) its parameters are of limited usefulness. In view of the hierarchical organization of natural systems, use of the Zipf-Mandelbrot model, developed in accordance with information theory, is proposed. Various examples of natural communities were fit to this latter model to produce an analysis of community structure in relation to the physical environment and the biological response of component organisms. The Zipf-Mandelbrot model was found to provide a good statistical description of the structure and transtormation of natural communities, under the assumption that the habitat can be considered hierarchical in structure.
\end{abstract}

\section{INTRODUCTION}

The attempt to satisfactorily explain species abundance patterns in natural communities has been a topic of considerable controversy in ecology. Since numerical dominance is a characteristic feature of communities (Yodzis 1978), researchers have applied quantitative models to data sets of species abundance, in an effort to seek general applicability and a better understanding of community organization. The most common models are the geometric series model (Motomura 1932), the broken-stick model (MacArthur 1957), the log-series model (Fisher et al. 1943) and the log-normal model (Preston 1948), and various reviews can be found in the literature (Pielou 1975, May 1976, Frontier 1985, Hughes 1986, Gray 1987). In particular, the lognormal distribution has received thorough consideration, since it is the expected pattern in undisturbed, fully developed communities (Patrick 1973, Bazzaz 1975, Gray 1978, Gray \& Mirza 1979, Gray \& Pearson 1982, Ugland \& Gray 1982, Jeffrey \& Hallegraeff 1987). In contrast, Lambshead \& Platt (1985), Nelson (1987), and, in particular, Hughes $(1984,1985,1986)$ have argued that the log-normal (like the log-series) distribution does not furnish any explanation of underlying ecological mechanisms. The main criticism of these models can be summarized under the following points: (1) lack of a theoretical basis in ecology (Hughes 1986); (2) poor fits (Frontier 1985, Hughes 1986, Gray 1987); and (3) lack of appropriate goodness of fit tests (Engen 1978). Hughes $(1984,1985,1986)$ put forward an iterative simulation model (known as the dynamics model'), which provides an explanation, based on interspecific competition, for the high number of species of low abundance and the low number of species of high abundance sometimes found in natural communities. The model includes parameters based on biological processes (recruitment, survivorship), and claims to provide a realistic approach to the subject.

The present paper calls into question 2 aspects of the dynamics model, namely, its prediction that competition is the main factor influencing community structure, and hence its dominance-diversity curve, and the limited ecological utility of the model's parameters. Because natural systems tend to exhibit a hierarchical organization (Frontier 1985), the Zipf-Mandelbrot model (Mandelbrot 1982), generated in accordance with information theory, is put forward as a more versatile model. Mandelbrot's approach to explaining the regular rank-frequency distributions amongst the words of a language was solved by linking the cost of transmitting information, hence the need to optimise 


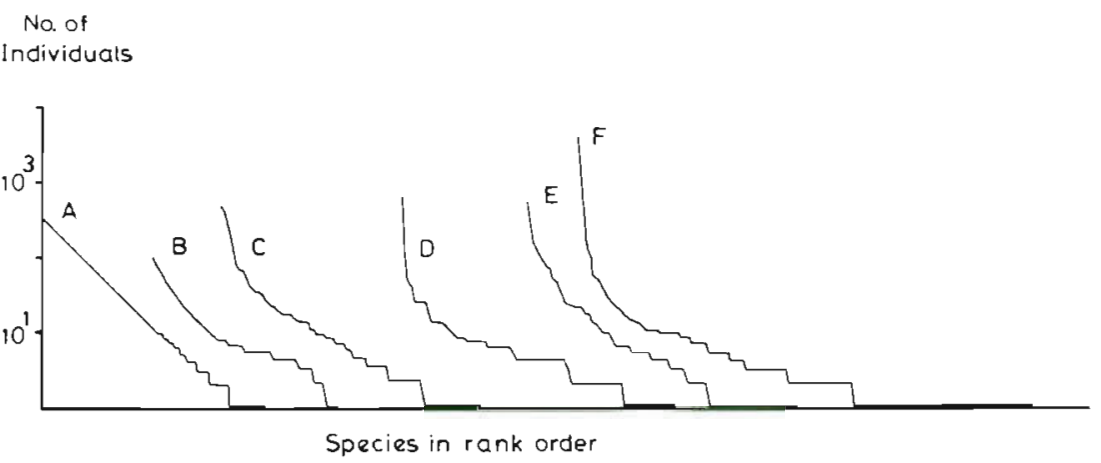

Fig. 1. Dominance-diversity curves for a log-series distribution (A), a log-normal distribution (B), the dynamics model (C). Hustedt's diatom collection (D), construction-set pieces (E), and sumames from the Barcelona telephone book $(F)$. A, B, and $\mathrm{C}$ redrawn after Hughes (1986) codes, and the cost of different words in a language. A similar approach to the analysis of dominance-diversity curves can offer some insight into the link between the probabilities of encountering different combinations of environmental conditions and the appearance of species according to their requirements. Finally, it is suggested that the usefulness of species abundance patterns as descriptors of community structure will advance as more refined models of the hierarchical structure of ecological systems are elaborated.

\section{SHORTCOMINGS OF THE DYNAMICS MODEL}

The dynamics model 'predicts a concave dominancediversity curve with a larger number of rare species, but indicates that there may be a smaller proportion of rare species in communities where population growth is less restricted by competition or mortality' (Hughes 1986, p. 896) (Fig, 1, C). However, identical curves are obtained from the frequency of surnames in the Barcelona telephone book (Fig. 1, F), the number of species per genus in the Hustedt collection of diatom types (Simonsen 1987), which consists of 17000 samples taken from shelf and oceanic waters in different parts of the world in different years (Fig. 1, D), and the frequency of the different part types used to build a

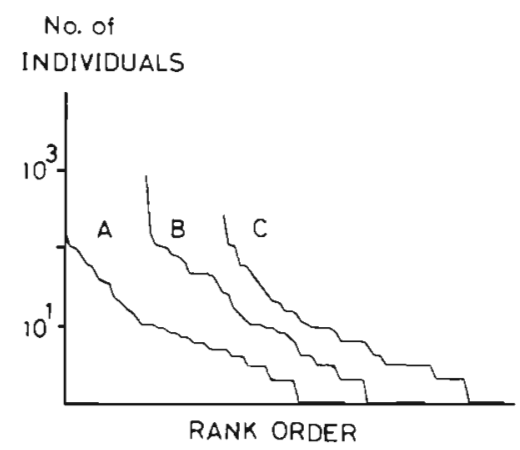

Fig. 2. Dominance-diversity curves for a benthic community off Cornwall (SW England) (Probert 1981) in June 1970 (A), May 1970 (B), and November 1970 (C). Compare with curves A, B, and $C$ in Fig. 1
'Meccano'-brand construction-set crane (Fig. 1, E), in which the effects of competition and/or mortality are, at the very least, questionable.

According to Pianka (1976), 'competition occurs when two or more organisms, or other organismic units, such as populations, interfere with or inhibit one another'. In line with this definition, several of the examples used by Hughes (1984) under the assumptions of the dynamics model can be criticized in that they do not strictly conform to the conditions of competition. Some group together data for several sampling years (Fig. $2 n$ in Hughes 1984) which, when broken down by month, yield different results (Fig. 2), more similar in shape to log-series (Fig. 2, A) or log-normal (Fig. 2, C) distributions. Most of the examples used by Hughes (1984) are in fact groupings of subsamples taken at a considerable distance from each other in time. Thus, despite the large horizontal (Hoghe 1982) and vertical (Fleeger \& Gee 1986, Hill \& Elmgren 1987) differences in benthic meiofauna in a matter of just a few centimeters, the example used by Hughes, based on Gage (1972), contained sixteen $10 \mathrm{~cm}^{2}$ cores of the top $20 \mathrm{~cm}$ of sediment taken from an area $100 \mathrm{~m}$ in diameter. Such a grouping would appear to invalidate any possible conclusion as to the effect of small-scale interspecific interactions like competition and predation, in view of the potential importance of spatial heterogeneity for understanding community structure (Holt 1987). The effect caused by combining samples is illustrated in Fig. 3. This example, presented by Rosenberg (1974), depicts the curves obtained by grouping $30 \times 30 \times 10 \mathrm{~cm}$ dredge samples taken off the coast of Sweden. The tail of the curve grows with the number of subsamples grouped together, indicating that there is no interaction between the species involved. The last curve, for a grouping of 20 subsamples, was the curve used by Hughes to test the dynamics model (Fig. 21 in Hughes 1984).

The dynamics model is based on the concavity of the curve, to a large extent generated by the large number of rare or transient species. Fig. 4 illustrates the importance of sampling area in generating such curves. For a given community, there will be a series of populations 


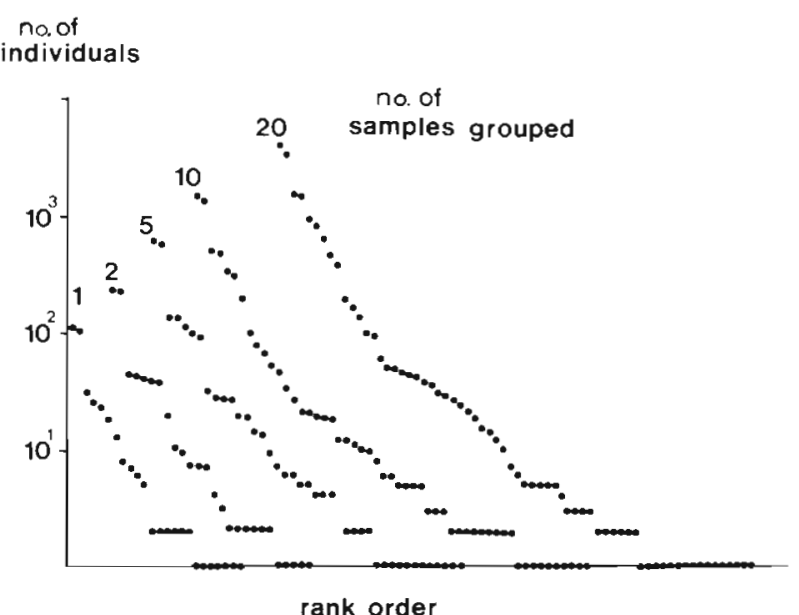

Fig. 3. Changes in dominance-diversity curves generated by grouping together samples from a community from off the coast of Sweden (Rosenberg 1974)

of abundant, more or less common, species ( $n$ in Fig. 4), whereas the rest of the species $\left(m_{\mathrm{i}}\right)$, because of their low frequency, form populations that are restricted to certain subsectors of the community, there being no predictable interaction between $m_{i}$ s or between certain $n^{\prime} s$ and $m_{\mathrm{i}}{ }^{\prime} s$. An increase in the number of rare species (but not intermediate and abundant species) with sample size was proved by Pearson et al. (1983). Even though, as Hughes states, the abundance of transient species is probably reduced by competition and predation, the shape of the curves generated by grouping samples will be invalid, unless the relative weights of the species can be adjusted (e.g. by using a log scale for the $\mathrm{x}$-axis).

As a result, in our view the dynamics model is not a valid explanatory model. Its shortcomings can be summarized as follows: (1) there is no evidence that this type of dominance-diversity curve is generated in all cases solely as a result of the action of competition or predation; (2) competition cannot be claimed to be the most important factor determining the dominancediversity curves, in that the data sets used do not fulfill the required conditions for testing this point; (3) the attractiveness of the dynamics model concept, rooted in the possibility of establishing conditions and then analyzing the resulting structure, is outweighed by the fact that few of its parameters have been or can be measured in the field (Gray 1987).

\section{AN ALTERNATIVE APPROACH}

A community is a system made up of various subsystems (e.g. taxa, trophic levels, size classes), each of which is, in turn, made up of individual elements; in other words, it is a hierarchical system like the ones

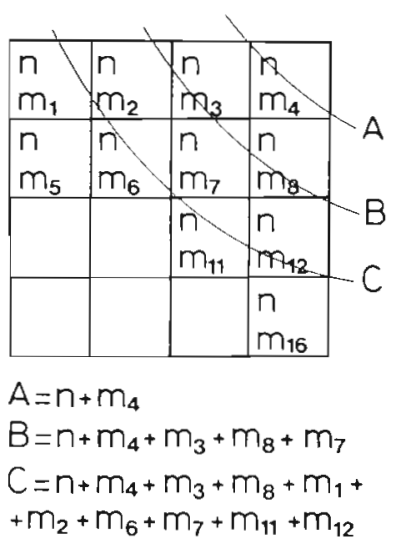

Fig. 4. Illustration of the influence of sampling area on dominance-diversity curves: $n=$ abundant species (common throughout the entire community: $m=$ transient species (generally differing between subareas)

used to describe astrophysical, biological, economic, social, and symbol systems (Winiwarter 1983). Hierarchy theory has made inroads into ecology in recent years (Sugihara 1980, Allen \& Starr 1982, Allen \& Wyleto 1983, Maurer 1985). The theory is based on the assumption that, although patterns of community structure are produced by a variety of interactions, such patterns can be considered independently of detailed knowledge about these interactions. Kolasa \& Strayer (1988) and Kolasa (1989) have proposed that the habitat may be conceived of as hierarchical in structure (e.g. forest - tree - branch - leaf), and that this structure may be responsible for the observed patterns of species abundance. In population biology, hierarchical systems consist of a large number of rare species (e.g. large organisms, organisms belonging to high trophic levels) (Frontier 1985, Kolasa 1989) as well as a high number of subsystems which assure the continuity of the main system even when certain subsystems (e.g. species) disappear (Roberts \& Tregonning 1980). The simplest mathematical expression for such systems is Zipf's law (Zipf 1949):

$$
\log F_{r}=F_{0}-\delta \log r
$$

where $F_{r}=$ frequency of species $r$; and $r=i$ ts position in the rank order. Plots using log-log scales minimize the role of the less abundant species, dependent on sampling. This model, improved by Mandelbrot (1982), was recently discussed by Frontier (1985) and expressed as:

$$
\log F_{r}=\alpha-\delta \log (r+\beta)
$$

The theory underlying the model is that the abundance of each species is also dependent upon the existence of a series of unspecified conditions (e.g. food consumption, mortality, reproduction rate, chemical defenses, adap- 
tive morphological evolution, interspecific interactions), as well as the existence of a number of preconditions that must be satisfied by the environment (Frontier 1985, Kolasa \& Strayer 1988). The larger the number of conditions the less likely it is that the species in question will be present, since the probabilities are multiplicative. The set was depicted by means of a truncated tree diagram (Fig. 21 in Frontier 1985). The parameter $\delta$ depends on the average probability of the appearance of a species, all preconditions necessary for that species being fulfilled. It takes on lower values in highly complex systems of information transmission, and higher values in less structured systems (Frontier 1985). The parameter $\beta$, for its part, depends on the average number of alternatives per category of precondition (i.e. the potential diversity of the environment). Thus, $\beta$ takes on higher values when the environment affords room for a greater number of conditions or alternatives. Both parameters $\delta$ and $\beta$ together are conditioning factors affecting the species diversity and evenness of the community. A value of $\delta$ close to 1 yields a greater degree of evenness than do higher values, while a positive value of $\beta$ results in a greater evenness among the most abundant species, and therefore a higher species diversity index. As Frontier (1985) pointed out, $\beta$ acts on species diversity and evenness through niche diversity (the number of alternatives for each type of environmental precondition), and $\delta$ on the predictability of the ecosystem (probability of appearance of a species when its environmental preconditions have been satisfied). In consequence, the model provides for an analysis of environmental conditions and then, once the environment has been defined, for an investigation of the response of the different organisms.

\section{FITTING MANDELBROT'S MODEL TO NATURAL DATA}

Three data sets from the literature were fitted using the Zipf-Mandelbrot model. The first (Pearson 1975) was an analysis of the development of a soft-bottom benthic community. Organic enrichment, caused by effluent material discharged by a pulp and paper mill, took place during the sampling period. Temporal changes in the model parameters are depicted in Fig. 5. The parameter $\beta$ took on low values during discharge. This can be interpreted as a reduction in the number of altematives supported by the environment, as the theory behind the model predicts. Relative fluctuations in the value of $\beta$ during discharge means that the parameters $\delta$ and $\beta$ should be evaluated as relative rather than as absolute values. On the other hand, $\delta$ took on lower values soon after discharge commenced, but recovered later on. In line with the theoretical

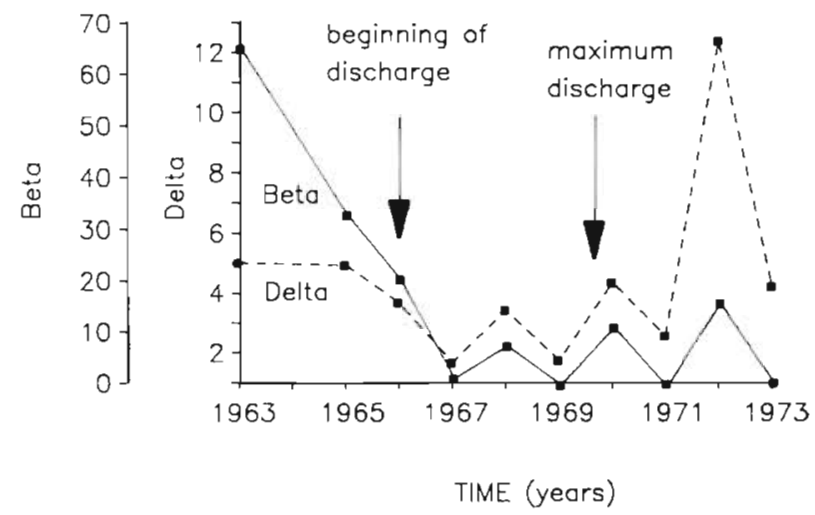

Fig. 5. Values of the parameters $\beta$ and $\delta$ of the Zipf-Mandelbrot model with time in a soft-bottom community off Scotland affected by organic enrichment (Pearson 1975)

description of the model, this should be interpreted as a reduction in community structure, especially after maximum discharge, the community being colonized by more opportunistic, less demanding species. The reduction in the diversity of the system over the sampling period (Pearson 1975) supports this conclusion. The relative decay in the value of $\delta$ at the beginning of the discharge should not be interpreted as an increase in community structure but rather as a complete change in the composition of the community.

The second example (Fig. 6) is a transect along Loch Etive, Scotland (Gage 1972). The parameter $\beta$ took on higher values close to the mouth of the firth and lower values closer to the open sea, except at Stn E-11, which was much deeper than the rest of the sampling stations. Thus, the environment afforded more room for different biological strategies (more possibilities) in the inshore area, where environmental variability increased, due to the influx of fresh water from the firth. In spite of this, the value of the parameter $\delta$ remained fairly constant, except for the deeper station E-11, suggesting that the

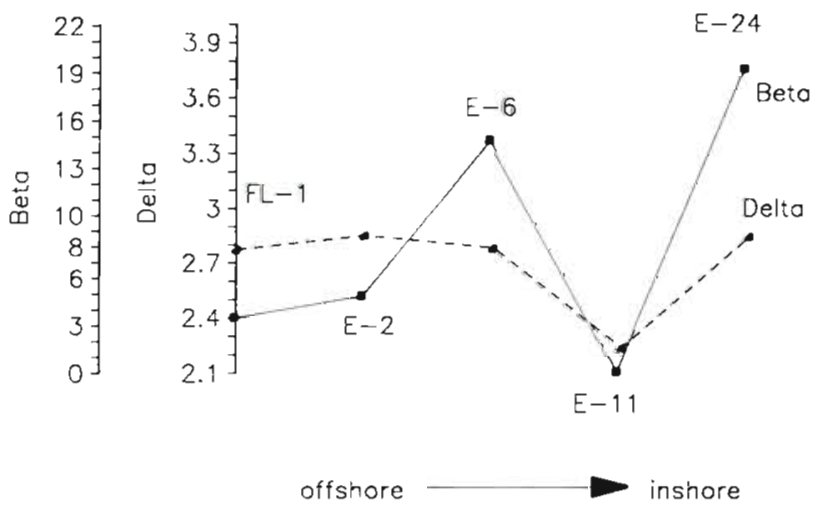

Fig. 6. Values of the parameters $\beta$ and $\delta$ of the Zipf-Mandelbrot model on a transect along Loch Etive in Scotland (Gage 1972) 
species present had similar requirements with regard to their colonization strategies or that the complexity of the different stations was relatively similar. Interestingly, Gage (1972) showed that the percentage of the polychaete-bivalve fraction remained fairly constant at between 50 and $70 \%$.

The last example (Fig. 7) has been taken from Probert (1981) and comprises 15 samples from an area affected by a discharge of china clay waste. Probert (1981) found that the community underwent impoverishment (a reduction in diversity), despite a reduction in the discharge during the study. Fluctuations in the parameter values were observed, following a generally declining trend. According to the theory, the system should afford fewer alternatives over time, but this was not accompanied by an increase in opportunistic species (parameter $\delta$ ). Despite the changes observed in the fauna, the author concluded that the fluctuations in relative species abundance were in accord with seasonal and long-term changes in coastal soft-bottom communities. In this example, the parameters followed parallel trends, suggesting that both the environment and the fauna were undergoing a similar pattern of change. In other words, as Probert (1981) pointed out, the discharge did not seem to affect the area, and changes were related to the normal transformations taking place in the community.

The quality of a model depends on how well it performs in relation to the purpose for which it was designed (Starfield \& Bleloch 1986). In consequence, the examples presented suggest that the Zipf-Mandelbrot model can be considered a good statistical descriptor of the transformation of natural communities and their structure. Nevertheless, 3 shortcomings were identified, and these must be taken into account in future applications: (1) the parameters are variable over time, hence the use of relative values rather than absolute values is encouraged; (2) the model affords useful information on community structure provided that additional information (diversity, composition, environmental changes) is also available; (3) the question of whether or not the least abundant species should be omitted from the curves generated (Frontier 1985) remains to be resolved. While logarithmic scales can be used to reduce the importance of this factor, species of low abundance generate steps in the final part of the curves, thereby affecting the parameter values

The use of hierarchical models to explain patterns of species abundance has been proposed previously by other workers (Sugihara 1980, Allen \& Starr 1982, Allen \& Wyleto 1983, Kolasa \& Biesiadka 1984, Maurer 1985, Kolasa \& Strayer 1988, Kolasa 1989). The Zipf-Mandelbrot model takes the line of a hierarchical view of systems as a useful means of understanding patterns in

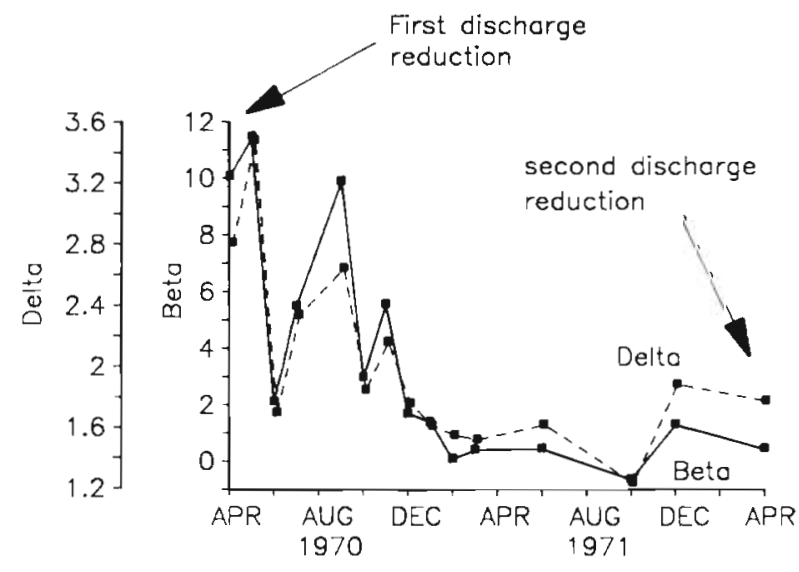

Fig. 7 Values of the parameters $\beta$ and $\delta$ of the Zipf-Mandelbrot model with time in a soft-bottom community of china clay waste deposits (Probert 1981)

community structure, and would seem to be a promising method of using frequencies of abundance to analyze community structure by means of optimization of community information systems. A thorough consideration of this model and its application to biological samples would be of exceptional interest in order to shed light on a subject for which few useful conclusions have been forthcoming from a quite copious literature.

Acknowledgements. The authors thank Drs Jordi Flos and Kevern Cochrane for carefully reading different versions of the manuscript and Mr R. Sacks for preparing the English version.

\section{LITERATURE CITED}

Allen, T F. H., Starr, T. B. (1982). Hierarchy: perspectives for ecological complexity. Univ. of Chicago Press, Chicago

Allen, T F. H., Wyleto, E. P. (1983). A hierarchical model for the complexity of plant communities. J. theor. Biol. 101 529-540

Bazzaz, F. A. (1975). Plant species diversity in old-field successional ecosystems in southern Illinois. Ecology 56: 485-488

Engen, S. (1978). Stochastic abundance models with emphasis on biological communities and species diversity, Chapman and Hall, London

Fisher, R. A., Corbet, A. S., Williams, C. B. (1943). The relation between the number of species and the number of individuals in a random sample of an animal population. $\mathrm{J}$. Anim. Ecol. 12: 42-58

Fleeger, J. W., Gee, J. M. (1986). Does interference competition determine the vertical distribution of meiobenthic copepods? J. exp. mar. biol. Ecol. 95: 173-181

Frontier, S. (1985). Diversity and structure in aquatic ecosystems. Oceanogr. mar. biol. A. Rev. 23: 253-312

Gage, J. (1972). Community structure of the benthos in Scottish sea lochs. I. Introduction and species diversity. Mar. Biol. 14: 281-297

Gray, J. S. (1978). The structure of meiofauna communities. Sarsia 64: 265-272

Gray, J. S. (1987). Species-abundance patterns. In: Gee, J. H. 
R., Giller, P. S. (eds.) Organization of communities. Past and present. Blackwell Scientific Publications, Oxford, p. $53-67$

Gray, J. S. Mirza, F. B. (1979). A possible method for detecting pollution-induced disturbance on marine benthic communities. Mar. Pollut. Bull 10: 142-146

Gray, J. S., Pearson, T. H. (1982). Objective selection of sensitive species indicative of pollution-induced change in benthic communities. I. Comparative methodology. Mar Ecol. Prog. Ser, 9: 111-119

Hill, C., Elmgren, R. (1987). Vertical distribution in the sediment in the co-occurring benthic amphipods Pontoporeia affinis and $P$. femorata. Oikos 49: 221-229

Hoghe, E. W. (1982). Sediment disturbance and the spatial distributions of shallow-water meiobenthic nematodes on the open Oregon coast. J. mar Res. 40: 551-573

Holt, R. D. (1987). Prey communities in patchy environments Oikos 50: $276-290$

Hughes, R. G. (1984). A model of the structure and dynamics of benthic marine invertebrate communities. Mar. Ecol. Prog. Ser 15: 1-11

Hughes, R. G. (1985). A hypothesis concerning the influence of stability and stress on the structure of marine benthic communities. In: Gibbs, P. E. (ed.) Proc. 19th Eur. Mar Biol. Symp. Cambridge University Press, Cambridge, p. $391-400$

Hughes, R. G. (1986). Theories and models of species abundance. Am. Nat. 128: 879-899

Jeffrey, S. W., Hallegraeff, G. M. (1987). Phytoplankton pigments and light climate in a complex warm-core eddy of the East Australian current. Deep Sea Res. 34: 649-673

Kolasa, J. (1989). Ecological systems in hierarchical perspective: breaks in community structure and other consequences. Ecology 70: 36-47

Kolasa, J., Biesiadka, E. (1984). Diversity concept in ecology. Acta Biotheor. 33: 145-1.62

Kolasa, J., Strayer, D. (1988). Patterns of abundance of species: a comparison of two hierarchical models. Oikos 53: $235-241$

Lambshead, J., Platt, H. M. (1985). Structural patterns of marine benthic assemblages and their relationship with empirical statistical models. In: Gibbs, P. E. (ed.) Proc. 19th Eur. Mar. Biol Symp. Cambridge University Press, Cambridge, p. $371-380$

Mandelbrot, B. B. (1982). The fractal geometry of nature. W. H. Freeman and Co., San Francisco

MacArthur. R. A (1957). On the relative abundance of bird species. Proc natn. Acad. Sci. U.S.A. 43: 293-295

Maurer, B. A. (1985). Avian community dynamics and desert grasslands: observational scale and hierarchical structure. Ecol. Monogr 55: 295-312

May, R. M. (1976). Patterns in multispecies communities. In

This article was submitted to the editor
May, R. M. (ed.) Theoretical ecology. Principles and applications. Blackwell Scientific Publications, Oxford, p. 197-227 (2nd edn 1981)

Motomura, I. (1932). A statistical treatment of associations. Zool. Mag. Tokyo 44: 379-383 (in Japanese)

Nelson, W. G. (1987). An evaluation of deviation from the lognormal distribution among species as a pollution indicator in marine benthic communities. J. exp. mar. Biol. Ecol. 113: 181-206

Patrick, R. (1973). Use of algae, especially diatoms, in the assessment of water quality. Am. Soc. for Testing and Materials, Special Techn. Publ. 528: 76-95

Pearson, T. H. (1975). The benthic ecology of Loch Linnhe and Loch Eil, a sea-loch system on the west coast of Scotland. IV Changes in the benthic fauna attributable to organic enrichment. J. exp. mar. Biol. Ecol. 20: 1-41

Pearson, T. H., Gray, J. S., Johannessen, P. J. (1983). Objective selection of sensitive species indicative of pollutioninduced change in benthic communities. 2. Data analyses. Mar. Ecol. Prog. Ser 12: 237-255

Pianka, E. R. (1976). Competition and niche theory. In: May, R. M. (ed.) Theoretical ecology. Principles and applications. Blackwell Scientific Publications, Oxford, p. 167-193 (2nd edn 1981)

Pielou, E. C. (1975). Ecological diversity. Wiley-Interscience, New York

Preston, F. W. (1948). The commonness, and rarity, of species. Ecology 29: 254-283

Probert, P. K. (1981). Changes in the benthic community of china clay waste deposits in Mevagissey Bay following a reduction in discharge. J. mar. biol. Ass. U.K. 61: 789-804

Roberts, A., Tregonning, K. (1980). The robustness of natural systems. Nature, Lond. 288: 265-266

Rosenberg, R. (1974). Spatial dispersion of an estuarine benthic faunal community. J. exp. mar Biol. Ecol. 15: 69-80

Simonsen, R. (1987). Atlas and catalogue of the diatom types of Friedrich Hustedt, Vol. I. J. Cramer, Berlin

Starfield, A. M, Bleloch, A. L. (1986). Building models for conservation and wildlife management. MacMillan, New York

Sugihara, G. (1980). Minimal community structure: an explanation of species abundance patterns. Am. Nat. 116: 770-787

Ugland, K. I., Gray, J. S. (1982). Lognormal distributions and the concept of community equilibrium. Oikos 39: 171-178

Winiwarter, P. (1983). The genesis model. Part II: Frequency distributions of elements in self-organized systems. Spec. Sci. Tech. 6: 103-112

Yodzis, P. (1978). Competition for space and the structure of ecological communities. Springer Verlag, Berlin

Zipf, G. K. (1949). Human behaviour and the principle of Least Effort. Hafner, New York (2nd edn 1965)

Manuscript first received: January 3, 1990

Revised version accepted: October 11, 1990 